\title{
ICTs in inclusive education for learning disabilities
}

\author{
TICs na educação inclusiva para deficiências de aprendizagem \\ Las TIC en la educación inclusiva para las discapacidades del aprendizaje
}

Received: 07/14/2021 | Reviewed: 07/19/2021 | Accept: 07/22/2021 | Published: 07/29/2021

Panagiota Anagnostopoulou ORCID: https://orcid.org/0000-0002-2244-4871 N.C.S.R. 'Demokritos, Greece E-mail: italgiota@gmail.com

Georgia Lorentzou ORCID: https://orcid.org/0000-0001-8805-4625 N.C.S.R. 'Demokritos', Greece E-mail: georgialor@gmail.com

Athanasios S. Drigas

ORCID: https://orcid.org/0000-0001-5637-9601 N.C.S.R. 'Demokritos', Greece E-mail: dr@iit.demokritos.gr

\begin{abstract}
The current paper gives a brief description of the role of ICTs in the inclusion of children with autism, ADHD, and dyslexia. Therefore, many researchers note that ICTs play a key role in inclusive education and help to bridge the digital gap. Thus, the research team of this paper presents specific examples of ICTs that aid children with learning difficulties. ICTs promote the equal participation of all students in the educational system and consequently prepare them for everyday life outside of the school. The use of ICTs and assistive technology in the educational processes will have positive effects in the inclusion of children with learning difficulties and help them solidify the newly acquired knowledge as well as develop their consciousness.
\end{abstract}

Keywords: ICTs; Inclusion; Learning disabilities; Autism; ADHD; Dyslexia.

\section{Resumo}

O presente artigo fornece uma breve descrição do papel das TICs na inclusão de crianças com autismo, TDAH e dislexia. Portanto, muitos pesquisadores observam que as TICs desempenham um papel fundamental na educação inclusiva e ajudam a preencher a lacuna digital. Assim, a equipe de pesquisa deste artigo apresenta exemplos específicos de TICs que auxiliam crianças com dificuldades de aprendizagem. As TICs promovem a participação igual de todos os alunos no sistema educacional e, consequentemente, os preparam para a vida cotidiana fora da escola. O uso das TICs e da tecnologia assistiva nos processos educacionais terá efeitos positivos na inclusão de crianças com dificuldades de aprendizagem e ajudá-las a solidificar os conhecimentos recém-adquiridos, bem como a desenvolver sua consciência.

Palavras-chave: TICs; Inclusão; Dificuldades de aprendizagem; Autismo; TDAH; Dyslexia.

\section{Resumen}

El presente artículo ofrece una breve descripción del papel de las TIC en la inclusión de niños con autismo, TDAH y dislexia. Por lo tanto, muchos investigadores señalan que las TIC desempeñan un papel clave en la educación inclusiva y ayudan a cerrar la brecha digital. Así, el equipo de investigación de este artículo presenta ejemplos específicos de TIC que ayudan a los niños con dificultades de aprendizaje. Las TIC promueven la participación equitativa de todos los estudiantes en el sistema educativo y, en consecuencia, los preparan para la vida cotidiana fuera de la escuela. El uso de las TIC y la tecnología asistencial en los procesos educativos tendrá efectos positivos en la inclusión de los niños con dificultades de aprendizaje y les ayudará a solidificar los conocimientos recién adquiridos así como a desarrollar su conciencia.

Palabras clave: TIC; Inclusión; Problemas de aprendizaje; Autismo; TDAH; Dislexia.

\section{Introduction}

Students with learning difficulties use assistive technology to access standard tools, to complete educational tasks, and to participate equally with their peers in the educational environment. Assistive technology is capable of dealing with many types of learning disabilities. For example, a child who has difficulty in writing can write a text by dictating it and turning it 
into a written report with special software. A child with math problems can use a handheld calculator to keep score while playing a game with a friend. A child who cannot speak may need a communication device, such as a language synthesizer, to participate in the lesson. ICTs (Information and Communication Technologies) can help children with learning difficulties develop their hearing, math, organization, memory, reading, and writing skills (Adebisi, Liman \& Longpoe, 2015).

As a result of technological progress, ICTs created the so-called "digital divide". Some people are not able to respond individually to this progress but the proper use of ICTs can help them overcome this disadvantage, participate in the digital society in a more equal way and have better employment opportunities. Besides, the creation and implementation of support programs for people with disabilities are also economically advantageous. Long-term care is more expensive than supported independence (Benda, Havlícek, Lohr \& Havránek, 2011).

According to Njoki and Wabwoba (2015), the ultimate goal of social inclusion is to enable people to improve their lives by seizing opportunities. ICTs have bridged the gap in distance education by allowing students and teachers to be even on different continents during the course. With e-education, those who cannot have a physical presence in schools are not excluded from education. Electronic libraries, virtual labs, and computer games have also been created to simplify learning (Njoki \& Wabwoba, 2015).

Electronic games have been found to help children with learning disabilities adopt appropriate health-related behaviors by developing skills such as imagination, attention, and self-control. Virtual and augmented reality creates an environment that provides interest and motivation to children with learning difficulties and develops their motor and perceptual skills. Also, mobile applications help children with learning difficulties become independent and perform their daily activities (Papanastasiou, Drigas, Skianis, Lytras \& Papanastasiou, 2018).

It is necessary to create a supportive school environment, which will promote the development of each student. The teacher of the class has nowadays an ally in the learning process, the ICTs, (Obradović, Bjekić \& Zlatić, 2015). ICTs help to create an individualized teaching program for children with learning difficulties and an environment where the student comes into contact with the educational material and can interact with it. Additionally, ICTs help students to communicate with each other, but also with the class teacher through special devices. It is also pointed out that ICTs can be used as an evaluation tool, as they save time and money (Williams, Jamali \& Nicholas, 2006).

According to Della Volpe (2016), the use of technology in education creates a flexible curriculum that enhances the equal participation of students with learning difficulties and their preparation for daily life outside of school. The right to education concerns all children without exceptions and it is essential for the personal development of every human being. Below there are some examples of ICTs and their contribution to the inclusion of students with autism, ADHD, and dyslexia.

\section{Methodology}

In our research we followed the method of literature review of articles. Initially, our search focused on articles from the last five years. However, we considered it necessary to include specific older articles for a more complete and accurate investigation of the issue. So the coverage period that was used was from 2013 to 2020 . The data bases that were used in the study were Google scholar and Mendelay and we searched with the following keywords: ICTs, Inclusion, learning disabilities, autism, ADHD, dyslexia.

The basic criteria for selecting viable materials were that the main topic of the articles had to be the use of ICTs for the development of children with autism, ADHD and dyslexia. In addition, the results of the use of ICTs had to be clear and effective. Also, the included articles must have been published in the last 8 years and the language of the studies must have been in English (Igwenagu, 2016). 


\section{Results and Discussion}

\subsection{ICTs and Autism}

Autism is a disorder that is affecting more and more people. It is a lifelong developmental disorder that prevents people from properly understanding what they see, hear, and generally feel. As a result, they face serious problems on a personal, social, academic, and professional level. Autism spectrum disorder is characterized by difficulties in socializing and communicating and several obsessive behaviors (Block, Block \& Halliday, 2006). Students with autism benefit from the use of ICTs, as they learn to manage the stress for inclusion into society, develop their reading and social skills, and help with their communication.

Different technological types have been used in autism intervention. The use of social robots and mobile learning is very common. Also, a lot of research has focused on serious games and virtual and augmented reality. It is also worth mentioning that, according to studies, artificial intelligence has positive effects on the diagnosis of autism. Machine learning applications, fuzzy logic techniques, natural language processing, neural networks, and mobile applications have much to offer in autism assessment (Anagnostopoulou, Alexandropoulou, Lorentzou, Lykothanasi, Ntaountaki \& Drigas, 2020).

The Facial Expression Wonderland (FEW) application was designed to improve the ability of students with autism to recognize expressions. FEW is a daily training tool consisting of different levels. It requires students with autism to use the application daily to improve their skills in recognizing facial expressions and developing the "Theory of Mind" (the ability to understand the mental state of other people). The real impact of the FEW application has not yet been assessed and must be assessed in the future (Drigas \& Ioannidou, 2013). Tang et al. (as mentioned in Conde \& Fonseca, 2017) investigated the usefulness of applications for children with autism based on gestures that aim at involving the children in the activity.

The research of Jaliawala and Khan (2018) presents some Computer Vision Assisted Technologies (CVAT), which help the people who belong to the autism spectrum recognize and produce facial expressions. One CVAT technology that helps people with autism improve their nonverbal skills is FaceFlower, which uses a flower that grows with the user's expressions. The purpose was to help individuals pronounce their feeling and exercise their facial muscles with a specific expression so that they could see the plant grow (Jaliawala \& Khan, 2018).

Also, virtual reality programs (VR) actively help people with autism. Virtual Interactive Training Agent (VITA) aims to improve people's interviewing skills to find work more easily. The research of Burke et al. (2018), states that the VITA program was designed to give users with autism the opportunity to practice a professional interview by answering the questions of a $\mathrm{VH}$ interviewer.

The serious game SEMA-TIC aims to teach literacy skills to children with poor functional language skills and autism. The game includes feedback and reinforcements that align with the children's interests, such as bright and moving objects. Each game is considered to train specific literacy skills, such as word recognition, alphabet, syntax, and so on. Grossard et al. (2018) developed an innovative electronic learning and communication game called JEMImE. The game aims to educate the facial expressions of children with autism in social settings.

The Queball robot, which is spherical like a ball, helps children with autism develop their social skills. Its software is simple but at the same time provides a variety of kinetic, visual, and audio features that integrate the child more easily into the game. According to the results, the device can be easily used at school and the child's interaction with the robot was characterized as calm, entertaining, and interesting (Ntaountaki, Lorentzou, Lykothanasi, Anagnostopoulou, Alexandropoulou \& Drigas, 2019).

At the same time, robots can help children with autism improve their emotional recognition skills (Ntaountaki, Lorentzou, Lykothanasi, Anagnostopoulou, Alexandropoulou \& Drigas, 2019). For example, the Probo robot was used to test whether children with autism can recognize emotions in specific situations. According to the results, the performance of the 
participants improved significantly. Therefore, it is demonstrated the important role that robots can play in autism intervention. Some robots used to develop skills in children with autism were: Nao, Kaspar, Charlie, QT Robot, IrobQ, CARO, and KiliRo (Grossard, Palestra, Xavier, Chetouani, Grynszpan \& Cohen, 2018).

David Lima and Thais Castro (2012) introduced Music Spectrum, a virtual music environment for children with autism, based on the theory that music therapy can promote positive change. The aim was to awaken the person with autism to a more dynamic interaction from exploring an organ to participating in a social group.

A mobile application which is called PARLE (Portable Affect Reference Learning Environment) can be used to translate transfers into simpler forms (Vlachou \& Drigas, 2017). Another application, which is called "MOSOCO", uses augmented reality and helps children practice their social skills in real situations. This application provides children with autism with interactive features to encourage them to have eye contact, maintain appropriate boundaries in space, and share their interests (Escobedo, Nguyen, Boyd, Hirano, Rangel, Garcia-Rosas, Tentori \& G. Hayes, 2012). The iPad application "Go Talk Now Free", has a similar format to the communication system PECS (Picture Exchange Communication System), as it makes all the options visible on the touch screen and the child can choose a picture freely (Muharib, Correa, Wood \& Haughney, 2018).

Díaz-Escudero et al. (2018) studied the Taimun-Watch system, which guides self-regulation in people with autism through a smartwatch and a smartphone. People with autism wear the smartwatch and it monitors their heart rate. When the signal exceeds a predetermined limit, emotional self-regulation strategies appear on the watch screen. Therefore, family, teachers, and caregivers can guide people with autism through asynchronous interventions that help the person deal with situations that usually lead to frustration, anger, or anxiety. The interface is designed in such a way that even non-experts are allowed to create emotional self-regulation strategies. Strategies consist of steps or cards with multimedia content: pictograms, photos, text, or animation (Díaz-Escudero, Torrado, Gomez \& Montoro, 2018).

Another means of intervention on the autistic spectrum is augmented reality glasses, which primarily aid in the learning of socio-emotional skills. Augmented reality (AR) allows the user to interact with the environment, while virtual objects and audio assistance are provided through a visual overlay and speakers respectively (Sahin, Abdus-Sabur, Keshav, Liu, Salisbury \& Vahabzadeh, 2018).

\subsection{ICTs and ADHD}

Attention Deficit Hyperactivity Disorder (ADHD) is a serious disorder of psychological development characterized by persistent symptoms of inattention, hyperactivity, and impulsivity that exist in two or more environments for more than six months (Gkeka, Gougoudi, Mertsioti \& Drigas, 2018).

Applications have been designed to help people with attention deficit hyperactivity disorder (ADHD). Bul et al. (2015) developed a serious game called Plan-It Commander. The purpose of its design was to promote behavioral learning and everyday life skills such as time management, organization, and other skills aimed at promoting social acceptance, where children with ADHD often lag.

Social robots, such as Topobo and RUBI, can help educate children with social and cognitive disorders and other disabilities. A research involving children with ADHD found that children with limited attention skills worked with the robot throughout the intervention without the need for a break. These results show the potential of robots as an educational tool in special education and their positive effects on children with ADHD (Alexopoulou, Batsou \& Drigas, 2019).

Also, as reported by Gkeka et al. (2018), the tangible user interface (TUI) was also found to be important in the learning experience. The immediate operation makes the touch screen attractive to users and significantly influences learning processes by stimulating motivation and increasing their engagement. So TUI can be one of the primary factors that contribute 
to the enhanced involvement of students with ADHD.

At the same time, the virtual reality video game industry (Microsoft Kinect, Nintendo Wii) allows the person to monitor himself during the interaction and possibly reduce his excessive movement. Also, computers in the classroom can present material in different ways. Computer programs help in the design and mapping of the mind which improves the organization and flow of writing that are necessary for students with ADHD (Gkeka, Gougoudi, Mertsioti \& Drigas, 2018).

According to research, the use of a laptop by students with ADHD helps in the organization of their daily program. The device compensates for their organizational and memory difficulties as students emphasize their work and their notes (Drigas, Ioannidou, Kokkalia \& Lytras, 2014). It has also been shown that the movement and use of gestures improve the learning skills of people with ADHD. Therefore a system that promotes movement by allowing gestures, as well as hand-eye coordination using a natural user interface (Natural User Interface), seems to be a very good solution for improving attention (Garcia-Zapirain, Torre Díez \& López-Coronado, 2017).

Another system that works on mobile phones and helps children with ADHD and their families in establishing a healthy breakfast and bedtime routine by providing specific structures, as well as rewards, is MOBERO. According to the results of the research of Sonne et al. (2016), the use of MOBERO was associated with lower levels of parental confusion during breakfast and sleep and increased independence of children.

In contrast, the Chillfish operating system does not provide help for specific routines but is a relaxing biofeedback game. By breathing on a simple Lego fish the child controls a virtual fish in a virtual underwater world. Chillfish's goal is to collect as many starfish as possible by performing a relaxing breathing exercise. Another application is TimeTimer, which is a commercial product available in a wristband and mobile application and helps people stay focused by visualizing the time left for a job. CogoLand, on the other hand, is a game based on an avatar in the 3D world who must complete a race as fast as possible. The speed of the avatar is controlled by the child's level of concentration, which is measured using electroencephalography (EEG). Finally, the Cogmed computer application trains the child's working memory (Sonne, Marshall, \& Obel, 2016).

BlurtLine is designed to help the child avoid impulsive speech. He achieves this by using an interactive chest strap that serves both as a sensor and as an intervention tool that provides the child with tactile feedback. CASTT focuses on helping children regain and retain their attention during lessons. CASTT is based on accelerometers that detect when a child loses attention and a mobile application helps him to regain it (Smit \& Bakker, 2015).

Sonne et al. (2016) introduced the ParentGuardian application, which provides behavioral strategies for parents of children with ADHD to support them in managing stressful situations. The ParentGuardian system uses changes in skin conductivity, measured by an electro-dermal activity bracelet, to calculate a parent's stress level. When a high level is detected, the application sends a reminder of the use of control strategies to the parent's mobile.

Also, another supportive technology for children with ADHD is SmartPen, which is designed to detect the loss of concentration of children during reading and to help them regain it. Through a built-in accelerometer and a machine learning algorithm, Smart Pen can recognize reading patterns. Smart Pen discreetly reminds children to resume reading either by turning on a small light or with a small vibration (Sonne, Marshall, Müller, Obel \& Grønbæk, 2016).

Ahmad, Parhizkar, and Pillay (2019) developed a mobile phone game that includes functions used to maintain the attention of the child with ADHD. They performed an experiment in which children with ADHD played the game voluntarily and their actions were recorded. Based on his results, the children showed a high percentage of interest in the game. This suggests that mobile games can help enhance the level of attention and concentration of students with ADHD.

Attention Exercise provides attention and memory enhancement exercises. Another application is EpicWin, which turns daily tasks into games, while Home Routines gives rewards for each task completed within a specific time. The Koi Pond 
application provides people with ADHD with relaxation exercises when they feel confused (Lewandowski, Wood \& Miller, 2016). Some computer games that aim to improve attention, memory, cognitive skills, and general executive functions are BrainTrain, Luminosity, and Play Attention (Lewandowski, Wood \& Miller, 2016).

Avila-Pesantez et al. (2018) studied the effectiveness of an Augmented Reality Serious Game (ARSG) called ATHYNOS. Users could play two games. The first was a Drag and Drop game and the second was a shapes game. In the Drag and Drop activity, the children improved the coordination of the eyes and hands.

Learning and communication electronic games (serious games) are considered a powerful mechanism that can be used to prevent mental disorders in children with ADHD. They can be described as "digital games and equipment with educational design beyond entertainment" (Grossard, Palestra, Xavier, Chetouani, Grynszpan \& Cohen, 2018). The research findings of Avila-Pesantez et al. (2018) showed that children after using ATHYNOS improved their attention. Voluntary participation and ongoing interest in problem-solving contribute to academic success and learning.

Tavakoulnia et al. (2019) designed a study aimed at understanding the contribution of applications and mobile devices in enhancing the executive functions of children with ADHD. A smartwatch was used by 24 students aged 10 to 13 years. The device enables the recording of the child's emotions and mood through the application "Keep Your Balance" so that the parent or caregiver monitors his progress and provides the user with help to control and guide his behavior through reminders with "The Coaching App". The smartwatch has proven to be an easy-to-use, useful, and safe device for children with ADHD (Tavakoulnia, Guzman, Cibrian, Lakes, Hayes \&. Schuck, 2019).

Also, as mentioned above, ICTs help children with ADHD control themselves and their behavior. Specifically, as reported by Bashiri, Ghazisaeedi, and Shahmoradi (2017), virtual environments provide motivation, reduce the stimuli that disorganize children with ADHD, and thus maintain their attention and concentration. Interventions based on virtual environments help to improve the perceptual skills of children with ADHD, such as attention, working memory, and executive functions. It seems that children with ADHD prefer interventions that contain technology to traditional techniques, as they feel more secure in such an environment (Bashiri, Ghazisaeedi \& Shahmoradi, 2017).

Finally, Schuck et al. (2016) presented a pilot study that aims to explore the effectiveness of the "iSelfControl" application, which was designed to support the control of students with ADHD in the classroom. Students had to evaluate their behavior every 30 minutes and record the data in the application to earn points, focusing on compliance, following rules and guidelines, and building social relationships. The class teacher also observed the children's behavior and scored the corresponding points. The children could be given feedback from the application. In conclusion, the application "iSelfControl" is an important tool for the design of individualized teaching that will address the needs and capabilities of the student with ADHD (Schuck, Emmerson, Ziv, Collins, Arastoo, Warschauer, Crinella \& Lakes, 2016).

\subsection{ICTs and Dyslexia}

There are four main types of technology used to facilitate the learning of children with dyslexia. These are text to speech, eye tracking, virtual learning environments, and games (Jing \& Chen, 2017). Interactive e-books allow readers to record their voices while reading. Also, they allow the reader to listen and practice parts of the word in order to improve phonetic awareness, as well as the ability to memorize and recognize words.

Read-Aid is a supportive reading tool that helps children with dyslexia to improve their reading patterns. Intervention with this tool helps speed reading, comprehension, and error reduction. Another software that supports reading is Sprint. Sprint adds speech to a computer, so the software can read the text displayed on the computer. The above software is very useful in detecting errors as it can read the texts written by the child (Jing \& Chen, 2017).

Al-Edaily et al. (2013) designed a system for dyslexia using the "Dyslexia Explorer" eye-tracking system. Initially, 
Dyslexia Explorer captures eye movement when a student reads texts. An algorithm is then used to filter where the gaze "sticks". Finally, the system analyzes the duration of these "glues" and their spatial distribution. As a result, eye-tracking technology allows specialists to detect reading problems and phonological difficulties in order to design effective programs for students with dyslexia.

The DysEggxia game was designed to improve the spelling skills of children with dyslexia. It includes 5000 exercises with different levels of difficulty. MathLexic is an interactive application that aims to improve the math skills of children with dyslexia. Specifically, it provides exercises for recognizing numbers, sequences, mathematical symbols, and mathematical functions (Ahmad, Jinon \& Rosmani, 2013).

A kindergarten child cannot be diagnosed with dyslexia. If, however, he presents some language difficulties that could potentially lead to dyslexia then early intervention is needed. For example, e-books can be used to encourage children's language skills through fun activities. The GraphoGame game was also designed to help kindergarten children with early signs of dyslexia recognize and distinguish vocal sounds. The game is simple, accessible and gives instant feedback, and rewards (Richardson \& Lyytinen, 2014).

Cidrim \& Madeiro (2017) introduced the EasyLexia mobile phone software, which consists of spelling, memory, and math problems activities for children with dyslexia. Abracadabra (ABRA) and e-Pearl software also benefit from letter-sound recognition, phonological awareness, and reading comprehension. Children who used these programs, showed learning benefits in the written language and had a better performance in their metacognitive reading skills.

Adebisi, Liman, and Longpoe (2015) mentioned assistive technologies for improving the written language, reading, and math. Speech recognition systems allow the child to speak to the computer through the microphone and the spoken words are displayed as texts on the computer screen. The Optical Character Recognition (OCR) allows the child to type text on the computer, while the speech composer reads the text back and forth loudly for the child to hear and see the text at the same time. Also, electronic math worksheets help children with arithmetic problems to organize basic math sets using a computer.

SEVERI is an e-learning environment for students with reading, writing, and comprehension difficulties. It includes tools such as instruction messages, a learning diary, a library, and discussion material. Also, "The Number Race" was developed as a computer game to intervene in dyscalculia. This software aims to educate children in a fun way, introducing problems tailored to the level of performance of each individual (Drigas \& Ioannidou, 2013).

Ebner et al. (2017) presented an educational platform for German-speaking users aged 8 to 12 with special educational needs. The aim was to provide elementary school students with a tool to improve their writing and spelling skills. With this tool, students can write and publish texts that are automatically evaluated. The system provides students with feedback on their mistakes, which helps to improve their writing and spelling skills. Besides, the exercises are presented according to the errors and the level of the user (Conde \& Fonseca, 2017).

Also, lately, it is very common to use games in education (Gamification in Education). One of the main opportunities for using gamification is the field of educational technology. Motivation is an important part of education, strongly influencing the extent to which students use effective learning strategies. Gooch, Vasalou, Benton and Khaled (2016) used classDojo (https://www.classdojo.com) as a gamification platform. This platform is quite popular as it has 2.4 million registered teachers and 53 million students in 180 countries.

\section{Conclusion}

We came to the conclusion that the use of ICTs offers many advantages. ICTs can become an alternative and reliable tool for inclusive education, as they support access to information and knowledge, the learning process, and the student-teacher interaction. 
Children with learning difficulties benefit from their interaction with ICTs. Initially, the time of the intervention process has been reduced and it is possible to process and classify large volumes of data. In addition, ICTs offer a more predictable and attractive environment to the children who feel more secure and actively involved in the intervention process. Also, ICTs activate their various senses with the help of pictures, graphs, videos, and develop learning strategies. Thus, the results of the research show higher success rates and accuracy and the therapist acquires a better picture of the capabilities and needs of the child.

However, it is important that the intervention is individualized and emphasis is placed on the needs and abilities of each child. Assistive technologies must be user-friendly, environmentally friendly, low cost, and easy to find and use. In conclusion, based on the literature, ICTs help in better understanding, assimilating, and consolidating the cognitive materials such as mathematics and language by all students. Regarding students with special needs, in many cases, ICTs are the only solution for their access to knowledge, information, and learning.

In conclusion, ICTs help to bridge the digital divide and promote digital inclusion as they contribute to the equal participation of people with learning difficulties in social activities and offer them better career opportunities. Future research should focus on the impact of ICTs at the vocational rehabilitation of children with learning disabilities In addition, a very interesting topic for further research is to explore ways to reduce the cost of applications in order to make them more accessible to families. After all, the ultimate goal is to include children with learning difficulties into society and so that they can feel equal and useful members.

\section{References}

Adebisi, R. O., Liman, N. A. \& Longpoe, P. K. (2015). Using Assistive Technology in Teaching Children with Learning Disabilities in the 21st Century. Journal of Education and Practice, 6 (24), 14-20.

Ahmad, I. S., Parhizkar, B. \& Pillay, S. O. (2019). Engaging Children with ADHD using Mobile Based Games. International Journal of Communication and Networking System, 6 (1), 11-15.

Ahmad, S., Z., Jinon, N., I. \& Rosmani, A., F. (2013). MathLexic: An assistive multimedia mathematical learning aid for dyslexia children. Business Engineering and Industrial Applications Colloquium (BEIAC), 2013 IEEE.

Al-Edaily, A., Al-Wabil, A. \& Al-Ohali, Y. (2013). Dyslexia Explorer: A Screening System for Learning Difficulties in the Arabic Language Using Eye Tracking. First International Conference for Human Factors in Computing and Informatics, SouthCHI 2013, Lecture Notes in Computer Science, 7946, 831834.

Alexopoulou, A., Batsou, A. \&. Drigas, A.S. (2019). Effectiveness of Assessment, Diagnostic and Intervention ICT Tools for Children and Adolescents with ADHD, International Journal of Recent Contributions from Engineering, Science \& IT (IJES), 7 (3), 51-63.

Anagnostopoulou, P., Alexandropoulou, V., Lorentzou, G., Lykothanasi, A., Ntaountaki, P. \& Drigas, A (2020). Artificial Intelligence in Autism Assessment. International Journal of Emerging Technologies in Learning (IJET), 15 (6), 95-107.

Avila-Pesantez, D., Rivera, L., A., Vaca-Cardenas, L., Aguayo, S. \& Zuniga, L. (2018). Towards the improvement of ADHD children through augmented reality serious games: Preliminary results. IEEE Global Engineering Education Conference, EDUCON, 843-848, April 2018.

Bashiri, A., Ghazisaeedi, M. \& Shahmoradi, L. (2017). The opportunities of virtual reality in the rehabilitation of children with attention deficit hyperactivity disorder: A literature review. Korean Journal of Pediatrics, 60 (11), 337-343.

Benda, P., Havlícek, Z., Lohr, V. \& Havránek, M. (2011). ICT helps to overcome disabilities. Agris On-Line Papers in Economics and Informatics, 3 (4), 6369.

Block, M. E., Block, V. E. \& Halliday, P. (2006). What is autism? Teaching Elementary Physical Education, 16 (6), 7-11.

Bul, K., Franken, I., Van der Oord, S., Kato, P., Danckaerts, M., Vreeke, L., Willems, A., van Oers, H. J. J., van den Heuvel, R., van Slagmaat, R. \& Maras, A. (2015). Development and User Satisfaction of "Plan-It Commander," a Serious Game for Children with ADHD," Games for Health Journal, 4 (6), 1-11.

Burke, S., Bresnahan, T., Li, T., Epnere, K., Rizzo, A., Partin, M., Ahlness, R.M. \& Trimmer, M. (2018). Using Virtual Interactive Training Agents (ViTA) with Adults with Autism and Other Developmental Disabilities. Journal of autism and developmental disorders, 83 (3), $905-912$.

Cidrim, L. \& Madeiro, F. (2017). Tecnologias da Informação e da Comunicação (TIC) aplicadas à dislexia: revisão de literature, Revista CEFAC , 19 (1), 99108.

Conde, M. \& Fonseca, D. (2017). Information Society Skills: Is Knowledge Accessible for All? Part I. Universal Access in the Information Society, 17, 223227. 
Della Volpe, V. (2016). Examination on ICT integration into Italian Education. Education and E-learning, 1 (1), 1-7.

Díaz-Escudero, A., Torrado, J. C., Gomez, J \& Montoro, G. (2018). Technology-aided authoring tools for ASD coaching support. Interacción 2018: Proceedings of the XIX International Conference on Human Computer Interaction, 18, 1-6, September 2018.

Drigas, A. S., Ioannidou, R. E., Kokkalia. G. \& Lytras, M. D (2014). ICTs, mobile learning and social media to enhance learning for attention difficulties. Journal of Universal Computer Science, 20 (10), 1499-1510.

Drigas, A. S. \& Ioannidou R. E. (2013). Special education and ICTs. International Journal of Emeging Technologies in Learning, 8 (2), $41-47$.

Escobedo, L., Nguyen, D. H., Boyd, L. E., Hirano, S., Rangel, A., Garcia-Rosas, D., Tentori, M. \& Hayes, G. (2012). MOSOCO: A Mobile Assistive Tool to Support Children with Autism Practicing Social Skills in Real-Life Situations. CHI 2012 Session: Health and children, Austin, Texas, USA, May 5-10..

Garcia-Zapirain, B., de la Torre Díez, I. \& López-Coronado, M. (2017). Dual System for Enhancing Cognitive Abilities of Children with ADHD Using Leap Motion and eye-Tracking Technologies. Journal of Medical Systems, 41 (7).

Gkeka, E. G., Gougoudi, A., Mertsioti, L. \& Drigas, A. S. (2018). Intervention for ADHD Child using the Montessori Method and ICTs. International Journal of Recent Contributions from Engineering, Science \& IT (IJES), 6 (2), 4-13.

Gooch, D., Vasalou, A., Benton, L. \& Khaled, R. (2016). Using gamification to motivate students with dyslexia. Conference on Human Factors in Computing Systems - Proceedings, 969-980.

Grossard, C., Palestra, G., Xavier, J., Chetouani, M., Grynszpan, G. \& Cohen, D. (2018). ICT and autism care: State of the art. Current Opinion in Psychiatry, $31(6), 474-483$.

Igwenagu, C. (2016). Fundamentals of research methodology and data collection. LAP Lambert Academic Publishing ( 2016-04-19 ). ISBN: 978-3-65986884-9.

Jaliawala, M. S. \& Khan, R. A. (2018). Can Autism be Catered with Artificial Intelligence Assisted Intervention Technology? A Literature Review, CoRR.

Jing, C., T. \& Chen, C., J. (2017). A Research Review: How Technology Helps to Improve the Learning Process of Learners with Dyslexia. Journal of Cognitive Sciences and Human Development, 2 (2), 26-43.

Lewandowski, L., Wood, W., \& Miller L., A. (2016). Technological Applications for Individuals with Learning Disabilities and ADHD. Computer-Assisted and Web-Based Innovations in Psychology, Special Education, and Health, 61-93.

Lima, D. \& Castro, T. (2012). Music spectrum: A Music Immersion Virtual Environment for children with Autism,” Procedia Computer Science, 14, 111-118.

Muharib, R., Correa, V. I., Wood, C., L., \& Haughney, K. L. (2018). Effects of Functional Communication Training using Go Talk Now iPad Application on challenging Behavior of Children with Autism Spectrum Disorder. Journal of Special Education Technology, 34 (2), 1-9.

Njoki, M., \& Wabwoba, F. (2015). The Role of ICT in Social Inclusion: A Review of Literature," International Journal of Science and Research (IJSR), 4 (12), 380-387.

Ntaountaki, P., Lorentzou, G., Lykothanasi, A., Anagnostopoulou, P., Alexandropoulou, V. \& Drigas, A. (2019). Robotics in Autism Intervention. International Journal of Recent Contributions from Engineering, Science \& IT (IJES), 7 (4), 4-17.

Obradović, S., Bjekić, D., \& Zlatić, L. (2015). Creative Teaching with ICT Support for students with Specific Learning Disabilities, Procedia - Social and Behavioral Sciences, 203, 291-296.

Papanastasiou, G., Drigas, A., Skianis, C., Lytras, M. \& Papanastasiou, E. (2018). Patient-centric ICTs based healthcare for students with learning, physical and/or sensory disabilities. Telematics and Informatics, 35 (4), 654-664.

Richardson, U. \& Lyytinen, H. (2014). The GraphoGame Method: The Theoretical and Mathodological Backround of the Technology-Enhanced Learning Environment for Learning to Read. Human Technology, 10 (1), 39-60.

Sahin, N., T., Abdus-Sabur, R., Keshav, N., Liu, R., Salisbury, J. P. \& Vahabzadeh, A. (2018). Case Study of a Digital Augmented Reality Intervention for Autism in School Classrooms: Associated With Improved Social Communication, Cognition, and Motivation via Educator and Parent Assessment. Frontiers in Education, 3 (57), 1-13.

Schuck, S., Emmerson, N., Ziv, H., Collins, P., Arastoo, S., Warschauer, M., Crinella, F. \& Lakes, K. (2016). Designing an iPad app to monitor and improve classroom behavior for children with ADHD: ISelfControl feasibility and pilot studies. PLoS ONE, 11 (10), 1-13.

Smit, D. \& Bakker, S. (2015). BlurtLine: A Design Exploration to Support Children with ADHD in Classrooms. Human-Computer Interaction - INTERACT 2015, 9299, Bamberg, Germany, August 2015.

Sonne, T., Marshall, P., Müller, J., Obel, C. \& Grønbæk, K. (2016). A follow-up study of a successful assistive technology for children with ADHD and their families. 15th International Conference on Interaction Design and Children, 400-407.

Sonne, T., Marshall, P., Obel, C., Thomsen, P. H. \& Gronbæk, K. (2016). An assistive technology design framework for ADHD. Proceedings of the 28th Australian Computer-Human Interaction Conference, OzCHI 2016, 60-71.

Tavakoulnia, A., Guzman, K., Cibrian, F., L., Lakes, K., D., Hayes, G. \& Schuck, S., E., B. (2019). Designing a wearable technology application for enhancing executive functioning skills in children with ADHD. UbiComp/ISWC 2019- - Adjunct Proceedings of the 2019 ACM International Joint Conference on Pervasive and Ubiquitous Computing and Proceedings of the 2019 ACM International Symposium on Wearable Computers, $222-225$. 
Research, Society and Development, v. 10, n. 9, e43410918230, 2021

(CC BY 4.0) | ISSN 2525-3409 | DOI: http://dx.doi.org/10.33448/rsd-v10i9.18230

Vlachou, J. A. \& Drigas, A. S. (2017). Mobile technology for students \& adults with Autistic Spectrum Disorders (ASD),” International Journal of Interactive Mobile Technologies, 11 (1), 4-17.

Williams, P., Jamali, H. \& Nicholas, D. (2006). Using ICT with people with special education needs: what the literature tells us. Aslib Proceedings: New Information Perspectives, 58 (4), 330-345. 